\title{
Treatment of Iron Deficiency with or without Anaemia with Intravenous Ferric Carboxymaltose in Gynaecological Practices - A Non-Interventional Study
}

\author{
Therapie des Eisenmangels mit oder ohne Anämie mit intravenöser Eisencarboxymaltose \\ in der gynäkologischen Praxis - eine nicht interventionelle Studie
}

Authors

Affiliations

\section{R. Herfs ${ }^{1}$, L. Fleitmann ${ }^{2}$, I. Kocsis}

Gynaecological Practice, Grünwald

2 Dortmund Gynaecology and Obstetrics, Dortmund

${ }^{3}$ Gynaecology and Obstetrics Practice, Bonn

\section{Key words}

- intravenous iron substitution

- ferric carboxymaltose

- iron deficiency anaemia

- hypermenorrhoea

- menorrhagia

- post partum

\section{Schlüsselwörter}

- intravenöse

Eisensubstitution

- Eisencarboxymaltose

- Eisenmangelanämie

- Hypermenorrhö

- Menorrhagie

- post partum

Deutschsprachige Zusatzinformationen online abrufbar unter: www.thieme-connect.de/ ejournals/toc/gebfra

\section{received 5.7.2013 \\ revised 29.11.2013 \\ accepted 2.12.2013}

\section{Bibliography}

DOI http://dx.doi.org/ 10.1055/s-0033-1360223

Geburtsh Frauenheilk 2014; 74: 81-88 @ Georg Thieme

Verlag KG Stuttgart · New York . ISSN 0016-5751

\section{Correspondence}

\section{Prof. Istvan Kocsis, MD}

Gynaecology and Obstetrics Practice

Mainzer Straße 45

53179 Bonn

kocsis.dr@t-online.de

\section{Abstract \\ $\nabla$}

In this multi-centre, prospective, non-interventional study, the effectiveness and tolerance of ferric carboxymaltose (ferinject ${ }^{\circledR} ;$ FCM) was tested through use in standard gynaecological practice. In total, data from 273 patients was evaluated. 193 of these patients displayed iron deficiency anaemia (IDA), and 68 had iron deficiency without anaemia (ID). The reasons for the ID/IDA were hypermenorrhoea (HyM) $(n=170)$, postpartum condition (PP) $(n=53)$ or another indication $(n=53)$. The average age of the patients was 40 years old, with $8 \%$ of them being vegetarians. Half of the patients had already been treated for anaemia, primarily with oral iron products (94\%). The primary, serious accompanying symptoms of anaemia were fatigue (72\%), lack of concentration (42\%), pale mucous membranes (42\%), headache (26\%) and sleep disorders (21\%). Only one patient did not show serious symptoms at the start of the study. The most frequent indications for parenteral therapy were the need for rapid iron substitution to reduce symptoms (>70\%), followed by the lower effectiveness or intolerance of oral products ( $42 \%$ each) as well as patients not completing the course of treatment with oral products (12\%). Patient information was collected at both the beginning and the end of the observation period, which lasted 15 weeks on average. FCM was most frequently administered via infusion (92\%; average infusion duration 21 minutes). Seven percent of patients received bolus injections. The average total iron dosage per patient was $788.7 \mathrm{mg}$ (median $550 \mathrm{mg}$; range: $50-3000 \mathrm{mg}$ ); the median individual dosage was $500 \mathrm{mg}$ (range: $50-1000 \mathrm{mg}$ ). The total dosage was, in most cases, administered through a single application (range: 1-10). Symptoms, blood values $(\mathrm{Hb})$, iron stores (serum-ferritin [S-ferritin]) and transport iron (transferrin saturation [TSAT]) normalised to a large extent. In all subgroups, 92\%

\section{Zusammenfassung \\ $\nabla$}

In dieser multizentrischen, prospektiven, nicht interventionellen Studie wurden Wirksamkeit und Verträglichkeit von Eisencarboxymaltose (ferinject ${ }^{\circledR}$; FCM) beim Einsatz in der gynäkologischen Praxisroutine geprüft. Insgesamt konnten Daten von 273 Patientinnen ausgewertet werden. Davon wiesen 193 Patientinnen eine Eisenmangelanämie (IDA), und 68 einen Eisenmangel ohne Anämie (ID) auf. Grund der ID/IDA waren Hypermenorrhö (HyM) $(n=170)$, Zustand post partum $(\mathrm{PP})(\mathrm{n}=53)$ oder eine andere Indikation $(n=53)$. Die Patientinnen waren im Durchschnitt 40 Jahre alt, $8 \%$ ernährten sich vegetarisch. Die Hälfte war antianämisch vorbehandelt, überwiegend mit oralen Eisenpräparaten (94\%). Die begleitenden schwer ausgeprägten Hauptsymptome der Anämie waren Fatigue (72\%), Konzentrationsschwäche $(42 \%)$, blasse Schleimhäute (42\%), Kopfschmerz (26\%) und Schlafstörungen (21\%). Nur eine Patientin war am Studienstart frei von schweren Symptomen. Indikationen zur parenteralen Therapie waren am häufigsten die Notwendigkeit rascher Eisensubstitution zur Symptomminderung $(>70 \%)$, gefolgt von mangelnder Wirksamkeit oder Unverträglichkeit der oralen Präparate (je 42\%) sowie mangelnde Therapietreue bei oralen Präparaten (12\%). Patientendaten wurden erhoben jeweils am Beginn und am Ende der Beobachtungszeit nach durchschnittlich 15 Wochen. FCM wurde am häufigsten mittels Infusion (92\%; mediane Infusionsdauer $21 \mathrm{~min}$ ) verabreicht. Bolusinjektionen erhielten $7 \%$ der Patientinnen. Die durchschnittliche totale Eisendosis pro Patient betrug 788,7 mg (Median $550 \mathrm{mg}$; Bereich: $50-3000 \mathrm{mg}$ ), die mediane Einzeldosis war 500 mg (Bereich: 50-1000 mg). Die Gesamtdosis wurde in Median mittels einer einzigen Applikation (Bereich: 1-10) verabreicht. Symptomatik, Blutwerte $(\mathrm{Hb})$, Eisenspeicher (Serum-Ferritin [S-Ferritin]) und Transporteisen (Transferrin- 
of women displayed a marked improvement in all of their symptoms. The average increase in Hb-value in the group as a whole was statistically significant, increasing from 10.5 to $13.0 \mathrm{~g} / \mathrm{dl}$. In the group with anaemia, the value increased from 9.9 to $13.3 \mathrm{~g} / \mathrm{dl}$, with $80 \%$ of women reaching normal Hb-values. The average $S$-ferritin value increased by a statistically significant $>70 \mu \mathrm{g} / \mathrm{L}$ from 17.2 to $88.8 \mu \mathrm{g} / \mathrm{l}$ and the value for the TSAT increased from $16.3 \%$ to $22.8 \%$. Seven patients reported experiencing side effects. None of the results were severe. Overall, as part of this non-interventional study for everyday routine in a gynaecological practice, a rapid improvement in symptoms accompanied by the rectification of iron deficiency and anaemia was shown with low occurrences of mild undesirable events, and therefore the data obtained from controlled clinical studies on the effectiveness and tolerance of intravenous ferric carboxymaltose could be confirmed.

\section{Introduction}

$\nabla$

There have been numerous international investigations into the treatment of iron deficiency (ID)/anaemia or iron deficiency anaemia (IDA) with regard to severity, diagnosis or aetiology [1$6]$. Women in particular are affected by iron deficiency with or without anaemia: up to $22 \%$ of women in industrialised nations are sufferers, while the figure is one in two women in developing countries $[1,2,7]$. There are three main conditions seen commonly in gynaecological practices that can lead to IDA: lack of iron intake $[8,9]$, hypermenorrhoea (HyM) [10] or pregnancy/postpartum condition (PP) [11-15]. Distressing symptoms of anaemia occur as a result of oxygen deficiency and the body's efforts to compensate for it: tiredness, irritability, skin and mucous membrane paleness, dizziness or apnoea. The following symptoms may additionally occur as a result of isolated ID: headache, cognitive disturbances, depression, in particular post-partum depression.

The rationale for treatment of IDA is ensuring systemic oxygen supply on the one hand and improving the prognosis of severe underlying illnesses on the other. The normalisation of anaemia also goes hand in hand with a considerable improvement in quality of life [16-19]. If the symptoms of iron deficiency are greatly pronounced and a change in diet, particularly in the case of a vegetarian diet, is not promising, medicinal iron substitution remains the treatment of choice for gynaecological indications in particular. The primary treatment method is through oral medication, which is replaced by parenteral preparations in the event of intolerance and/or ineffectiveness [20].

Indications for intravenous iron substitutions include uninfluenceable gastrointestinal intolerances to oral preparations [2, 21-27]. Alongside absolute ID through significant losses such as bleeding or through inadequate uptake, indications for parenteral iron treatment also include functional iron deficiency, tumour anaemia, anaemia from chronic illness and erythropoetin (EPO) $[2,22,26]$.

The comparison between different iron preparations administered orally or applied parenterally showed a significant need for easier to handle and better tolerated therapeutic alternatives. The iron ions released to varying degrees through the oral administration of iron preparations can lead to a broad spectrum of gastrointestinal irritations. With oral treatment, iron stores are only increased very slowly, meaning that oral treatment has to be sättigung [TSAT]) normalisierten sich weitgehend. In allen Subgruppen besserte sich die Gesamtheit der Symptome bei 92\% der Frauen drastisch. Der durchschnittliche Hb-Wert der Gesamtgruppe stieg statistisch signifikant von 10,5 auf $13,0 \mathrm{~g} / \mathrm{dL}$. In der Gruppe mit Anämie stieg der Wert von 9,9 auf 13,3 g/dL, $80 \%$ der Frauen erreichten normale Hb-Werte. Der Durchschnittswert des S-Ferritin stieg um $>70 \mu \mathrm{g} / \mathrm{L}$, ebenfalls statistisch signifikant, von 17,2 auf $88,8 \mu \mathrm{g} / \mathrm{L}$ und jener der TSAT von $16,3 \%$ auf $22,8 \%$. Sieben Patientinnen berichteten über Nebenwirkungen. Keines der Ereignisse war schwerwiegend. Insgesamt konnte im Rahmen dieser nicht interventionellen Studie für den gynäkologischen Praxisalltag eine rasche Symptomverbesserung, gekoppelt mit der Korrektur des Eisenmangels und der Anämie, bei geringem Auftreten von lediglich milden unerwünschten Ereignissen gezeigt und damit die aus kontrollierten klinischen Studien gewonnenen Daten zu Wirksamkeit und Verträglichkeit von intravenöser Eisencarboxymaltose bestätigt werden.

administered consistently over many months. The parenteral preparations used were iron-carbohydrate complexes, whereby there are significant differences with regard to stability or the incidence of anaphylactic reactions [28]. It is desirable for the iron complex to be highly stable in order to prevent the occurrence of toxic iron ions in the serum. Stable preparations can therefore be administered more quickly and in higher dosages [29].

Ferric carboxymaltose (ferinject ${ }^{\circledR}$ [FCM], Vifor Pharma) is a relatively newly developed, dextran-free iron complex with high complex stability. This enables the intravenous application of up to $1000 \mathrm{mg}$ of iron in a single dosage as a 15 minute short-term infusion [30]. Effectiveness, safety and tolerance have been documented by numerous controlled and randomised studies on over 6500 patients with different underlying illnesses, including patients with renal insufficiency [4,31], chronic inflammatory bowel diseases [32], cardiac insufficiency [33,34] as well as in women with hypermenorrhoea or post-partum anaemia $[4,13$, $22,35-38$ ]. The results of a meta-analysis of 14 phase III studies, in which a total of 2348 patients received iron carboxymaltose and 1978 patients received iron orally or intravenously or a placebo, confirm its positive effectiveness and safety profile [5]. According to the guidelines from the German Society for Haematology and Oncology (DGHO), ferric carboxymaltose offers the most effective option to substitute iron intravenously $[2,13]$. The study presented here aims to clarify to what extent the results of controlled prospective studies, including multicentred application under practice conditions, reflect how treatment with ferric carboxymaltose is carried out as part of the everyday routine at gynaecological practices with regard to dosage and application, and which advantages and disadvantages participants experience.

\section{Patients and Methods}

$\checkmark$

The analysis presented here is based on a prospective, non-interventional study on the treatment of iron deficiency with intravenously administered ferric carboxymaltose in gynaecological patients. Inclusion and exclusion criteria were the only binding stipulations in the study's observation plan. Diagnosis, treatment decisions and prescriptions, treatment in accordance with the information specified in the authorisation, as well as follow-up in accordance with the customary methods in the respective medi- 
cal practice and their documentation were the sole responsibility of the attending doctor [39]. The study was presented to the relevant authorities and associations, indicating all the necessary information, sent to the ethical commission of the Bavarian Medical Council for assessment and listed in the VfA (German Association of Research-Based Pharmaceutical Companies) register [40]. The study began in February 2011. The duration of the study was 15 months.

\section{Study aims and inclusion criteria}

The primary aims of the study were to test the effectiveness and tolerance of FCM under the conditions of a medical gynaecological practice in ID patients with or without anaemia caused by hypermenorrhoea, post-partum condition or other causes of iron deficiency. The primary endpoints of the data analyses were changes in Hb content, S-ferritin level, serum TSAT as well as the type and severity of accompanying clinical symptoms over the course of treatment. Secondary endpoints were the type and number of undesired events and changes in safety-related laboratory parameters, the evaluation of treatment regimes used in the practice as well as the type of anti-anaemic pretreatment and concomitant treatment. Inclusion criteria were female sex, age $\geq 18$ years, diagnosis of iron deficiency, FCM naivety, pre-existing treatment indication for FCM due to hypermenorrhoea (subgroup "HyM"), post-partum anaemia (subgroup "PP") or other non-obvious causes (subgroup "Other") as well as the patient having signed a written informed consent form. Exclusion criteria were pregnancy, chronic kidney disease, Crohn's disease, ulcerative colitis, heart failure or an active malignant process.

\section{Data collection, documentation and data analysis}

The two documentation dates were the day of acceptance into the study (baseline, BSL) and the end of the observation period (end of study, EOS). The envisaged duration of observation for each individual patient was 4 to 12 weeks, regardless of the number of consultations. The data collected by the practice as a matter of course through a standardised registration form which collects demographic basic information was also used for the study documentation, as was illness-related data from the patient history or ongoing observation. The effects of FCM in all patients as well as subgroups were analysed, stratified according to the reason for the iron deficiency ("HyM"; "PP") as well as according to the existence of iron deficiency with anaemia (IDA) or without anaemia (ID).

Before analysis, the data was checked for quality and plausibility as well as normal distribution. As in a non-interventional study there is no follow-up to complete the data sets beyond the data that the practice normally collects, this data is not always complete. This generally only enables evaluation through descriptive, statistical methods. The percentage frequency, the median with minimum and maximum values (range, spread), the quartiles, if applicable, and the average value are used to describe the frequency distribution. A two-way t-test per student was only used to describe the differences between BSL and EOS for the $\mathrm{Hb}$ and S-ferritin levels.

\section{Results}

$\nabla$

67 gynaecological practices in Germany participated in the study. Of the 303 patients recruited, 273 were treated with FCM and formed the safety group, with 271 being assessable and repre- senting the effectiveness group. Of these, 170 patients were assigned to the "HyM" subgroup, of which 117 (69\%) had iron deficiency anaemia ("IDA"). 53 patients were treated post partum, with only eight (15\%) of them having iron deficiency without concomitant anaemia ("ID"). The cause of ID could not be directly determined in 53 patients, 34 (64\%) of whom had anaemia ("Other"). Post-partum condition as well as hypermenorrhoea were given as the reasons for ID/IDA in five patients. Ten women were not able to be assigned to the IDA/ID groups due to a lack of relevant basic data (e.g. serum ferritin and TSAT).

\section{Patient demographics, anti-anaemia pre-treatment;} symptoms, anaemia and iron status at the start of the study

The average age of all patients was 40 years. Only women with post-partum condition ("PP") were younger, as expected, with an average age of 30.8 years. The most noticeable deviations from the average values were shown in the patients of the "Other" subgroup. They had a significantly lower body weight and were more likely to be vegetarian. The demographic information is detailed in 8 Table 1.

At the start of the study, anaemia was moderate on average (Hb $10.5 \mathrm{~g} / \mathrm{dL}$; S-ferritin $17.2 \mu \mathrm{g} / \mathrm{L}$ and TSAT $16.3 \%$ ) (cf. $\odot$ Tables 4 and 5). The clinical symptoms of fatigue, lack of concentration and pale mucous membranes were greatly pronounced in $72 \%$ and $42 \%$ of patients respectively. $61 \%$ of patients had been treated for anaemia in the six-month period prior to acceptance in the study. The oral administration of anti-anaemia medication was the most common form of administration (93\%). Iron injections were only administered to six women. Erythropoietin was not administered before or during the study. The most common reason for the introduction of intravenous FCM treatment was the necessity for rapid iron substitution (73\%) to get symptoms under control, followed by insufficient effectiveness (37\%) or lack of tolerance (35\%) to previous oral iron treatment.

\section{Duration of observation and iron treatment}

The average duration of observation for all patients was 15.1 weeks. Deviations from the average value in the subgroups were low (from - 0.6 in the case of "PP" to +1.1 in the case of "ID"). The average duration of treatment, defined as the period between the first and last administration of FCM, was 18.6 days. For the majority of patients $(n=250 ; 92.3 \%)$, treatment was administered according to plan in the observation period. The only additional treatment for anaemia, accompanying treatment with FCM, was oral iron substitution. The percentages of patients affected in the subgroups were as follows: "PP": $n=12$ (22.6\%); "HyM": $n=31$ (18.2\%); "Other": $n=7$ (13.2\%); "ID": $n=10$ (14.7\%) and "IDA": $\mathrm{n}=37(19.2 \%)$ of patients.

The average total iron dosage (TID) administered per patient was $788.7 \mathrm{mg}$ of iron, with a median value of $550 \mathrm{mg}$, over a broad range of $50-3000 \mathrm{mg}$. Table 2 shows the dosages in the subgroups. Differentiating TID by the HB levels at the start of the study resulted in a trend towards the administration of higher dosages in the case of a lower initial $\mathrm{Hb}$ value. The individual iron dosage applied (SID) was between 50 and $1000 \mathrm{mg}$. The most common (50\%) SID applied was between 500 and $1000 \mathrm{mg}$, with the median SID being $500 \mathrm{mg}$. Most patients (91.9\%) received FCM in the form of an intravenous drip (infusion), with 7\% receiving a bolus injection and $1.1 \%$ receiving both. The average number of applications was 2.1. The maximum value was 10 infusions. The duration of the intravenous drips was between 4 and 
Table 1 Demographic data for all subgroups.

\begin{tabular}{|c|c|c|c|c|c|c|}
\hline & \multicolumn{6}{|c|}{ Patient subgroups } \\
\hline & all $(n=271)$ & HyM $^{*}(n=170)$ & $\mathrm{PP}^{*}(n=53)$ & Other $(n=53)$ & ID $(n=68)$ & $\operatorname{IDA}^{\S}(n=193)$ \\
\hline \multicolumn{7}{|l|}{ Demographics } \\
\hline Average age (years) & 39 & 40.5 & 30.8 & 42.1 & 39.5 & 38.9 \\
\hline Average weight $(\mathrm{kg})$ & 67.8 & 68.8 & 69.9 & 63.2 & 68.5 & 67.7 \\
\hline Vegetarians (\%) & 8.2 & 7.1 & 9.4 & 9.4 & 8.8 & 8.3 \\
\hline \multicolumn{7}{|l|}{ BMI (\%) } \\
\hline$<26\left(\mathrm{~kg} / \mathrm{m}^{2}\right)$ & 76.3 & 75.6 & 69.2 & 86.3 & 74.6 & 77 \\
\hline $26-31\left(\mathrm{~kg} / \mathrm{m}^{2}\right)$ & 14.5 & 13.4 & 19.2 & 11.8 & 13.4 & 14.4 \\
\hline$>31\left(\mathrm{~kg} / \mathrm{m}^{2}\right)$ & 9.2 & 11 & 11.5 & 2 & 11.9 & 8.6 \\
\hline \multicolumn{7}{|l|}{ Risk factors (\%) } \\
\hline Diabetes & 1.8 & 0.6 & 5.7 & 1.9 & 0 & 2.6 \\
\hline Hypertension & 6.3 & 8.2 & 3.8 & 3.8 & 7.4 & 6.2 \\
\hline Smoking & 9.6 & 9.5 & 11.3 & 7.5 & 5.9 & 10.4 \\
\hline Obesity & 13 & 15.4 & 13.2 & 5.7 & 13.2 & 13.0 \\
\hline
\end{tabular}

Subgroups: Hypermenorrhoea (HyM), post partum (PP), other reasons (Other) as well as without anaemia (ID) or with anaemia (IDA)

* Post-partum condition as well as hypermenorrhoea were given as the reasons for ID/IDA in five patients.

$\S$ Ten patients were not able to be assigned to the anaemic/non-anaemic groups due to a lack of relevant basic data.

Table 2 Average dosage of intravenous ferric carboxymaltose ( $\mathrm{mg}$ iron).

\begin{tabular}{|c|c|c|c|c|c|c|}
\hline & \multicolumn{6}{|c|}{ Patient subgroups } \\
\hline & all $(n=271)$ & HyM* $^{*}(n=170)$ & $P^{*}(n=53)$ & Other $(n=53)$ & $\operatorname{ID} \S(n=68)$ & $\operatorname{IDA}^{\S}(n=193)$ \\
\hline \multicolumn{7}{|c|}{ Total iron dosage (mg) } \\
\hline M & 788.7 & 842.9 & 693.4 & 713.2 & 646.3 & 861.7 \\
\hline Range & $50-3000$ & $50-2500$ & $50-1500$ & $50-3000$ & $100-2000$ & $100-3000$ \\
\hline Median & 550 & 650 & 600 & 500 & 500 & 700 \\
\hline q1; q3 & $500 ; 1000$ & $500 ; 1000$ & $500 ; 1000$ & $500 ; 850$ & $500 ; 800$ & $500 ; 1000$ \\
\hline \multicolumn{7}{|c|}{ Individual iron dosage (mg) } \\
\hline M & 478.7 & 510.8 & 437.7 & 418.3 & 449.1 & 501.5 \\
\hline Range & $50-1000$ & $50-1000$ & $50-1000$ & $50-1000$ & $100-1000$ & $100-1000$ \\
\hline Median & 500 & 500 & 500 & 500 & 500 & 500 \\
\hline q1; q3 & $250 ; 500$ & $300 ; 500$ & $200 ; 500$ & $212.5 ; 500$ & $337.5 ; 500$ & $250 ; 500$ \\
\hline
\end{tabular}

Subgroups: Hypermenorrhoea (HyM), post partum (PP), other reasons (Other) as well as without anaemia (ID) or with anaemia (IDA)

$n=$ number of patients; $M$ = average value; range: minimum and maximum value; $q 1=25 \%$ quartile, $q 3=75 \%$ quartile

* Post-partum condition as well as hypermenorrhoea were given as the reasons for ID/IDA in five patients.

$\S$ Ten patients were not able to be assigned to the anaemic/non-anaemic groups due to a lack of relevant data.

70 minutes, with the median being 20 minutes. Lower or higher doses of iron were infused for the same length of time. The infusion volumes were between 10 and $250 \mathrm{ml}$ of physiological $\mathrm{NaCl}$ and the median was $153.3 \mathrm{ml}$. There was no trend towards the use of higher dilution volumes for higher individual doses. The details for the number of FCM infusions are shown in 0 Table 3.

\section{Symptoms, anaemia and iron status}

over the course of the study

The frequency of severe pronounced clinical symptoms at the start of the study: fatigue in $72.3 \%$ of patients, lack of concentration (42.1\%), pale mucous membranes (41.7\%), headache $(26.2 \%)$, alopecia (23.2\%), sleep disorders (21.4\%), depression (18.1\%), dyspnoea (14.4\%) and muscular symptoms/RLS (10.7\%). The frequency of individual symptoms does not differ significantly or systematically in the subgroups ( Fig. 1). An improvement in all symptoms was observed in a high percentage of patients $(n=243 ; 91.7 \%)$ and in all subgroups between BSL and EOS. Severely pronounced symptoms in particular such as fatigue, lack of concentration and pale mucous membranes decreased significantly in all subgroups. The number of completely symptom-free women increased from $1(0.4 \%)$ at BSL to $22(8.1 \%)$ at EOS.
The distribution of the $\mathrm{Hb}$ level at BSL corresponded to a leftskewed normal distribution: $6.5 \%$ of patients with $\mathrm{Hb}<8 \mathrm{~g} / \mathrm{dl}$, $30 \%$ with 8 to $<10 \mathrm{~g} / \mathrm{dl}, 41.7 \%$ with 10 to $<12 \mathrm{~g} / \mathrm{dl}$ and $21.9 \%$ with $\geq 12 \mathrm{~g} / \mathrm{dl}$. The Hb value for the effectiveness group increased from $10.5 \pm 1.79 \mathrm{~g} / \mathrm{dl}$ at BSL to $13.0 \pm 1.56 \mathrm{~g} / \mathrm{dl}$ at EOS. The average increase was $2.4 \pm 2.08 \mathrm{mg} / \mathrm{dl}$, with the difference between BSL and EOS being statistically significant. $79.7 \%$ of patients achieved normal $\mathrm{Hb}$ values $(\geq 12 \mathrm{~g} / \mathrm{dl}$ ) by EOS. In total, the $\mathrm{Hb}$ value increased by at least $\geq 1 \mathrm{~g} / \mathrm{dl}$ in 138 patients (71.5\%). Of these, 96 (49.7\%) displayed an increase by $\geq 2 \mathrm{~g} / \mathrm{dl}$ and 65 (33.7\%) by $\geq 3 \mathrm{~g} /$ dl. Table 4 shows the results of treatment, including for the subgroups, based on average values.

S-ferritin increased on average by $71.5 \pm 123.86 \mu \mathrm{g} / \mathrm{l}$ following intravenous FCM treatment. $\bigcirc$ Table 5 reflects the laboratory values. The increase is statistically significant. The BSL S-ferritin value of $88.9 \%$ of recorded patients $(n=162)$ was below the standard range. By EOS, this had been reduced to $9.9 \%$. There were no differences in values between patients with or without anaemia. The difference in TSAT between BSL and EOS could be determined in 46 patients. The average values increased from $16.3 \%$ to $22.8 \%$. Only $2(4.3 \%)$ of patients had normal TSAT values (20-45\%) at BSL, compared with 28 out of 46 patients at EOS (60.9\%). 


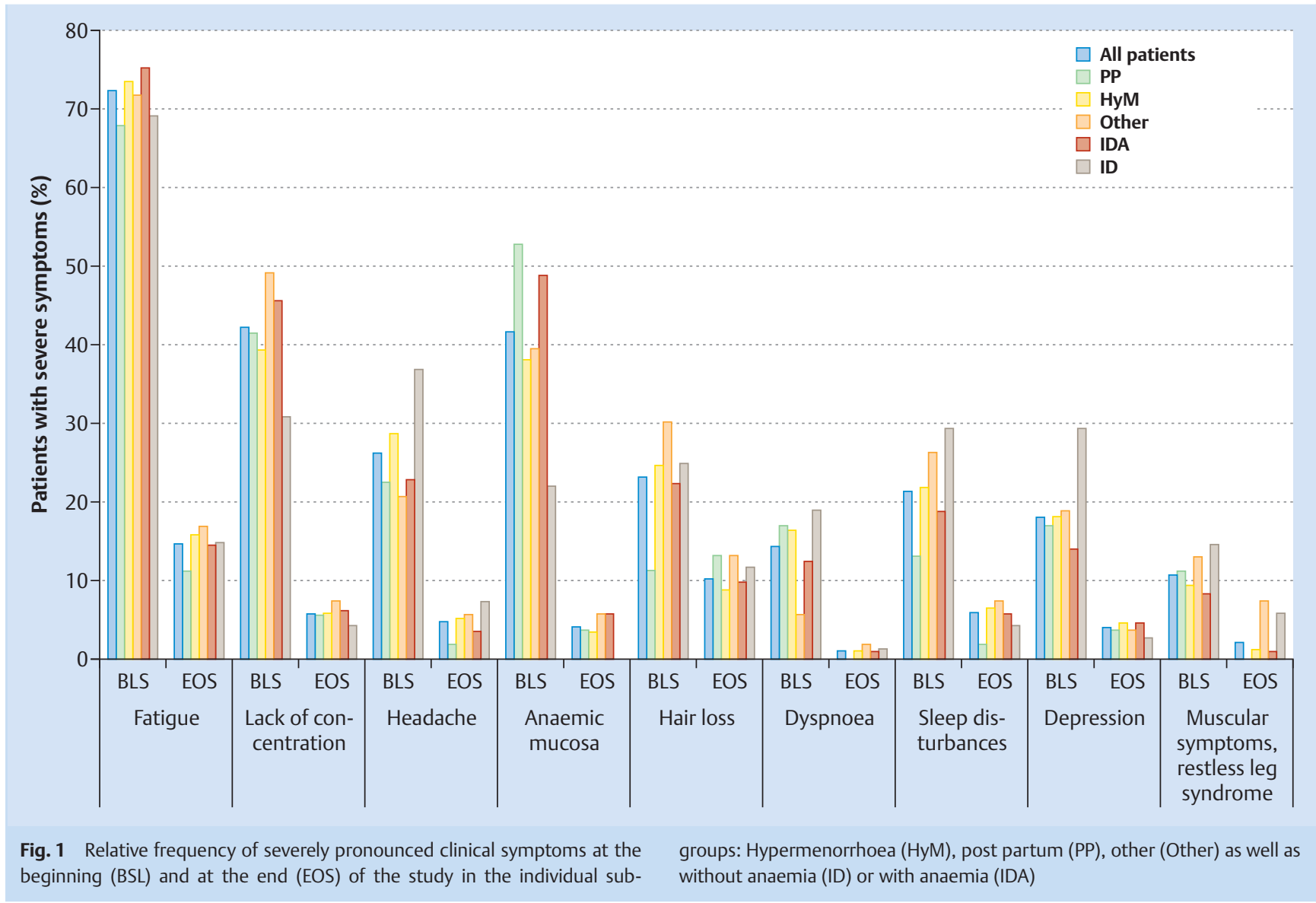

Table 3 Average number of intravenous ferric carboxymaltose applications.

\begin{tabular}{|c|c|c|c|c|c|c|}
\hline & \multicolumn{6}{|c|}{ Patient subgroups } \\
\hline & all $(n=271)$ & HyM $^{*}(n=170)$ & $\mathrm{PP}^{*}(n=53)$ & Other $(n=53)$ & $\operatorname{ID} \S(n=68)$ & $\operatorname{IDA}^{\S}(n=193)$ \\
\hline \multicolumn{7}{|c|}{ Number of infusions ( $n$ ) } \\
\hline Patients & 252 & 161 & 45 & 51 & 5 & 238 \\
\hline M & 1.9 & 2.0 & 1.5 & 2.0 & 2.2 & 1.9 \\
\hline Range & $1-10$ & $1-10$ & $1-3$ & $1-10$ & $1-4$ & $1-10$ \\
\hline \multicolumn{7}{|c|}{ Number of injections (n) } \\
\hline Patients & 22 & 11 & 10 & 2 & 0 & 21 \\
\hline M & 4.2 & 4.3 & 4.3 & 3.0 & $\varnothing$ & 4.3 \\
\hline Range & $1-10$ & $1-7$ & $1-10$ & $1-5$ & $\varnothing$ & $1-10$ \\
\hline \multicolumn{7}{|c|}{ Applications per patient ( $\mathrm{n}$ ) } \\
\hline Patients & 271 & 170 & 53 & 53 & 5 & 256 \\
\hline M & 2.1 & 2.1 & 2.1 & 2.1 & 2.2 & 2.1 \\
\hline Range & $1-10$ & $1-10$ & $1-10$ & $1-10$ & $1-4$ & $1-10$ \\
\hline
\end{tabular}

Subgroups: Hypermenorrhoea (HyM), post partum (PP), other reasons (Other) as well as without anaemia (ID) or with anaemia (IDA)

$\mathrm{n}$ = number of patients; $\mathrm{M}$ = average value; range: minimum and maximum value

* Post-partum condition as well as hypermenorrhoea were given as the reasons for ID/IDA in five patients.

$\S$ Ten patients were not able to be assigned to the anaemic/non-anaemic groups due to a lack of relevant data.

\section{Tolerance}

The safety group consisted of 273 women, with a total of 21 undesirable events (UE) being reported by seven women. Twelve UEs in five patients were designated as being certain or probable in relation to the medication. Four women reported mild hypersensitivity reactions (itching, urticarial rash or exanthema), one woman with pre-existing psoriasis, hashimoto thyreoditis and house dust allergy reported a severe hypersensitivity reaction (generalised urticarial rash, mild itching and nausea with a drop in blood pressure to $100 \mathrm{mmHg}$ ), with all patients recovering fully from the UEs. 
Table 4 Average $\mathrm{Hb}$ values $(\mathrm{g} / \mathrm{dl})$, their level, their average change $(\mathrm{m} \Delta-\mathrm{Hb})$ and the extent of normalisation $(>12 \mathrm{~g} / \mathrm{dl})$ between the start of the study $(\mathrm{BSL})$ and the end (EOS).

\begin{tabular}{|c|c|c|c|c|c|c|c|}
\hline & & \multicolumn{6}{|c|}{ Patient subgroups } \\
\hline & & all $(n=271)$ & HyM* $^{*}(n=170)$ & $\mathrm{PP}^{*}(n=53)$ & Other $(n=53)$ & ID ${ }^{\S}(n=68)$ & $\operatorname{IDA}^{\S}(n=193)$ \\
\hline \multirow[t]{2}{*}{ BSL } & Patients (n) & 247 & 154 & 51 & 47 & 54 & 193 \\
\hline & $\mathrm{Hb}(\mathrm{g} / \mathrm{dl})$ & 10.5 & 10.5 & 10.1 & 11.2 & 12.9 & 9.9 \\
\hline \multirow[t]{2}{*}{ EOS } & Patients (n) & 195 & 121 & 44 & 35 & 45 & 148 \\
\hline & $\mathrm{Hb}(\mathrm{g} / \mathrm{dl})$ & 13.0 & 13.0 & 12.8 & 13.1 & 13.3 & 12.8 \\
\hline \multirow[t]{2}{*}{$\mathrm{m} \Delta-\mathrm{Hb}$} & Patients (n) & 193 & 119 & 44 & 35 & 45 & 148 \\
\hline & $\Delta \mathrm{Hb}(\mathrm{g} / \mathrm{dL})$ & +2.4 & +2.5 & +2.7 & +1.8 & +0.5 & +3.0 \\
\hline Hb- $\uparrow$ standard & Patients (\%) & 79.7 & 80 & 86.5 & 69.6 & п. а. & 79.7 \\
\hline
\end{tabular}

Subgroups: Hypermenorrhoea (HyM), post partum (PP), other reasons (Other) as well as without anaemia (ID) or with anaemia (IDA)

$\mathrm{n}=$ number; $\mathrm{m} \Delta-\mathrm{Hb}=$ average change in $\mathrm{Hb}$ level; $\mathrm{Hb}$ - $\uparrow$ standard = increase of $\mathrm{Hb}$ within the standard range

* Post-partum condition as well as hypermenorrhoea were given as the reasons for ID/IDA in five patients.

$\S$ Ten patients were not able to be assigned to the anaemic/non-anaemic groups due to a lack of relevant data.

Table 5 Lab values for serum ferritin (S-ferritin) $(\mu \mathrm{g} / \mathrm{l})$ and transferrin saturation (TSAT) (\%) between the beginning of the study (BSL) and the end of the study (EOS).

\begin{tabular}{|c|c|c|c|c|c|c|c|}
\hline & & \multicolumn{6}{|c|}{ Patient subgroups } \\
\hline & & all $(n=271)$ & HyM $^{*}(n=170)$ & $\mathrm{PP}^{*}(n=53)$ & Other $(n=53)$ & ID ${ }^{\S}(n=68)$ & $\operatorname{IDA}^{\S}(n=193)$ \\
\hline \multicolumn{8}{|c|}{ S-ferritin ( $\mu \mathrm{g} / \mathrm{l})$} \\
\hline \multirow[t]{2}{*}{ BSL } & Patient (n) & 214 & 140 & 41 & 38 & 53 & 157 \\
\hline & M & 17.2 & 11.3 & 21.5 & 34.8 & 15 & 18 \\
\hline \multirow[t]{2}{*}{ EOS } & Patient (n) & 177 & 114 & 38 & 30 & 44 & 130 \\
\hline & M & 88.8 & 82.6 & 74.4 & 128.5 & 89.2 & 89.1 \\
\hline \multirow[t]{2}{*}{$\triangle \mathrm{BSL} / \mathrm{EOS}$} & Patient (n) & 162 & 107 & 35 & 25 & 43 & 116 \\
\hline & M & +71.5 & +73.1 & +57.6 & +81 & +76 & +70.4 \\
\hline$\uparrow$ standard & (\%) & 74.3 & 74.3 & 71.4 & 78.9 & 78.6 & 73 \\
\hline \multicolumn{8}{|l|}{ TSAT (\%) } \\
\hline \multirow[t]{3}{*}{ BSL } & Patient (n) & 85 & 52 & 18 & 16 & 12 & 72 \\
\hline & M & 16.3 & 12.2 & 16.1 & 30.3 & 10.3 & 17.6 \\
\hline & Median & 6 & 5 & 5.7 & 16.5 & 13 & 5.1 \\
\hline \multirow[t]{3}{*}{ EOS } & Patient (n) & 77 & 50 & 20 & 11 & 18 & 58 \\
\hline & M & 22.8 & 21.8 & 22 & 29.5 & 28.1 & 21.3 \\
\hline & Median & 21 & 21 & 20.4 & 30 & 26.5 & 20 \\
\hline \multirow[t]{2}{*}{$\triangle \mathrm{BSL} / \mathrm{EOS}$} & M & +12.8 & +13.5 & +8.3 & +15.7 & +22 & +38 \\
\hline & Median & +12.2 & +10.5 & +11.2 & +15.4 & +26 & +10.6 \\
\hline$\uparrow$ standard & (\%) & 64.3 & 66.7 & 50 & 83.3 & 71.4 & 61.8 \\
\hline
\end{tabular}

Subgroups: Hypermenorrhoea (HyM), post partum (PP), other reasons (Other) as well as without anaemia (ID) or with anaemia (IDA)

$\mathrm{M}=$ average value; $\uparrow$ standard $=$ increase in standard range, $\triangle \mathrm{BSL} / \mathrm{EOS}=$ difference between BSL and EOS

* Post-partum condition as well as hypermenorrhoea were given as the reasons for ID/IDA in five patients.

$\S$ Ten patients were not able to be assigned to the anaemic/non-anaemic groups due to a lack of relevant data.

\section{Discussion}

Proof of effectiveness in medicine is carried out through controlled, clinical studies of varying restrictive designs. They are set up in such a way that differences between groups can become as clear as possible. Unlike with controlled clinical studies, expert information is the only guide for the medication under investigation in non-interventional studies. In general, non-interventional studies contribute to the recording, representation and optimisation of the patient sample, incidences of illnesses and treatments, the type of methods used and the results of treatments, frequently under practice conditions. The inclusion of patients in a non-interventional study, the diagnosis as well as type and extent of therapeutic measures to be employed are at the discretion of the doctor; making decisions in advance or external interventions are not allowed $[40,41]$.
The multicentred, non-interventional study, carried out in a practice, using ferric carboxymaltose in gynaecological iron deficiency conditions presented here reflected the results found in many controlled gynaecological studies $[19,35,36,38]$ with ferric carboxymaltose. A direct numerical comparison between individual studies is problematic due to the differing study facilities, durations and aims. Nevertheless, some significant results can be compared.

In this non-interventional study, $\mathrm{a}+2.5 \mathrm{~g} / \mathrm{dl}$ increase in Hb values was seen over an observation period of 15 weeks. The corresponding values from controlled studies were around $+3 \mathrm{~g} / \mathrm{dl}$ $[35,36]$. The $\mathrm{Hb}$ value normalised, in the study presented, in $80 \%$ of patients, in comparison with between $73 \%$ and $91 \%$ in three controlled and randomised studies [19,35,36]. Under practice conditions, the increase of S-ferritin $(71.5 \mu \mathrm{g} / \mathrm{l})$ after 15 weeks was considerably lower than changes usually described in S-ferritin, i.e. of $+210 \mu \mathrm{g} / \mathrm{l}[35,36]$ after six weeks or of $+122 \mu \mathrm{g} / \mathrm{l}$ 
after 12 weeks [38]. The relationship with regard to the increase in TSAT is also similar, with an increase of $+13 \%$ in this study after 15 weeks, in comparison to $30 \%$ after six weeks [14] or $+23 \%$ after eight weeks [19] in other studies. It is to be considered in this case that the authors $[19,35,36]$ all described how, over the weeks following any iron replacement treatment, the S-ferritin and TSAT values that initially increased significantly decline considerably, but remain within the standard range. Furthermore, it is to be noted that, in the context of the controlled, randomised studies mentioned, patients were treated with total iron dosages that corresponded to the actual requirement, resulting in sufficient substitution. In this non-interventional study, there were no guidelines for this and therefore no guarantee that the quantity of iron required was actually substituted.

Nevertheless, it can be determined that, even under practice conditions, with an inhomogeneous patient population and greatly differing total iron dosages, results similar to those in previous clinical studies can be achieved. It is possible to control iron deficiency and anaemia in $80-90 \%$ of gynaecological patients through a low number of infusions in a way that is quick and well-tolerated. Alongside the significant improvement in symptoms, $\mathrm{Hb}$ values normalised on a long-term basis, with S-ferritin levels and TSAT also increasing. The greatly varying diagnostic and therapeutic approach in this study was also confirmed through larger national investigations and illustrates the need for a consistent treatment recommendation [42].

Gynaecological iron deficiency anaemia is present when $\mathrm{Hb}$ values in pregnant women, following birth or in the case of uterine bleeding, fall to $<11 \mathrm{~g} / \mathrm{dl}$ or $<12 \mathrm{~g} / \mathrm{dl}$, S-ferritin falls to $<30 \mathrm{ng} / \mathrm{ml}$ and TSAT to $<20 \%$ [25]. The extent to which the patients treated in the present study represent the conditions in every practice is unclear. The women in this practical study had moderate to severe anaemia and suffered from symptoms of severe tiredness with lack of energy, lack of concentration and pale mucous membrane. The low S-ferritin level confirmed absolute iron deficiency. The low co-morbidity determined showed that there were no indications of chronic inflammatory processes in patients. The primary underlying illness was hypermenorrhoea $(60 \%$, of which $72 \%$ were anaemic), followed by $19 \%$ each in the "PP" and "Other" groups. Half of the patients had been treated for anaemia within the six months prior to starting FCM treatment, with almost all of them taking iron orally.

The vast majority required urgent iron substitution in order to quickly improve symptoms, which was the case in all subgroups equally. Oral iron treatment proved not to be sufficiently effective in a third of women and was not tolerated by another third, with $12 \%$ displaying insufficient reliability in taking oral preparations, and only $2 \%$ having a contraindication for oral iron intake.

Iron substitution with FCM was almost exclusively administered through infusion. Bolus injections were given in $7 \%$ of cases, most frequently among women in the "PP" group. Over $50 \%$ of patients in all subgroups received individual dosages of between $500 \mathrm{mg}$ and $1000 \mathrm{mg}$ of iron (median $500 \mathrm{mg}$ ). The average total dosage in the subgroups was between $700 \mathrm{mg}$ and $800 \mathrm{mg}$, with the median being $500 \mathrm{mg}$. As expected, patients with anaemia received higher dosages than those without anaemia (average $700 \mathrm{mg}$ vs. $500 \mathrm{mg}$ ). The average infusion duration was 20 minutes and the average infusion volume was $150 \mathrm{ml}$ in all subgroups, whereby it was unimportant how high the respective quantity of active substance dissolved in it was. The findings from controlled, clinical studies regarding the very good tolerability of ferric carboxymaltose was verified in practice.
The specific advantages of ferric carboxymaltose over other parenteral or oral iron preparations as part of the everyday routine at gynaecological practices are considerable. The lower resorption rate and corresponding longer treatment time with limited gastrointestinal tolerance of oral iron medication are thus avoided [36]. This is particularly advantageous when quick iron substitution is needed. Iron dextran was widespread in intravenous iron therapy, as it can be infused in high doses up to $1000 \mathrm{mg}$, although infusion takes between three and six hours. Also of considerable importance when choosing ferric carboxymaltose as intravenous iron treatment is the fact that, with FCM, there is no danger of anaphylaxis caused by dextran antibodies, as has been reported when using high and low-molecular iron dextran $[11,43]$. In this respect, the development of the dextran-free formulations of iron-gluconate [44] and iron-sucrose [45] has already resulted in progress in terms of manageability and safety, as these preparations are complexes with an iron oxide/hydroxide core and a carbohydrate shell that are very stable, meaning that fewer free, toxic iron ions are released into the blood $[7,46,47]$. They too, however, have considerable disadvantages in comparison with ferric carboxymaltose. The problem is not only that lower iron quantities are infused, which takes considerably longer, but also that both are less stable than ferric carboxymaltose [48].

\section{Conclusion for Clinical Practice \\ $\nabla$}

In daily work at a gynaecological practice, a latent or manifest iron deficiency is often not diagnosed, as this is primarily not the reason for the medical consultation. This patient group is mainly made up of adolescent and young women in school or further education, whose iron deficiency is not a result of other underlying illnesses. These groups of young women are very aware of nutrition, but cannot guarantee a sufficient iron intake in a low-iron diet. Iron deficiency anaemia is inevitable in the case of chronic blood loss, e.g. through hypermenorrhoea. The consequences for this target group are striking: tiredness, learning deficit, lack of concentration, cognitive deficits, and all this in a time of life in which these abilities are of particular importance in order to ensure learning aims and education success.

Intravenous treatment with ferric carboxymaltose is easy to implement in gynaecological practices, is effective and is well-tolerated. The possibility of normalising iron levels even in the case of pronounced anaemia with only one or two applications over a short time keeps the strain on the patients and the expense for the practice low.

\section{Acknowledgements \\ $\nabla$}

The authors would like to thank all of the doctors, patients and medical personnel who took part and who made a great contribution to the study.

\section{Conflict of Interest \\ $\nabla$}

This paper was supported by Vifor Pharma Deutschland GmbH. Olof Harlin, Vifor Pharma Deutschland $\mathrm{GmbH}$, contributed to the composition of the manuscript. 


\section{References}

1 WHO; $C D C$. Assessing the iron status of populations 2004. Online: who. int/publications/2004/9241593156_eng.pdf; last access: 29.03.2012

2 Hastka J, Heimpel H, Metzgeroth G. Leitlinien der Deutschen Gesellschaft für Hämatologie und Onkologie (DGHO) zu Eisenmangel und Eisenmangelanämie 2011. Online: dgho-onkopedia.de/onkopedia/ leitlinien/eisenmangel-und-eisenmangelanemie; last access: 14.01.2014

3 McLean E, Cogswell M, Egli I et al. Worldwide prevalence of anemia. WHO Vitamin and Mineral Nutrition Information System 1993-2005. Public Health Nutr 2009; 12: 444-454

4 Lyseng-Williamson KA, Keating GM. Ferric carboxymaltose. A review of its use in iron-deficiency anemia. Drugs 2009; 69: 739-756

5 Moore AR, Gaskell H, Rose P et al. Meta-analysis of efficacy and safety of intravenous ferric carboxymaltose (Ferinject) from clinical trial reports and published data. BMC Blood Disorders 2011; 11: 4

6 Locatelli F, Pisoni RL, Combe C. Anemia in haemodialysis patients of five European countries: association with morbidity and mortality in the Dialysis Outcome and Practice Patterns Study (DOPPS). Nephrol Dialysis Transplant 2004; 19: 121-132

7 Dietzfelbinger H, Hubmann M. Eisenmangelanämie. DBI 2012; 2: 6-16

8 Deutsche Gesellschaft für Ernährung (DGE). Referenzwerte für die Nährstoffzufuhr. Online: http://www.dge.de/modules.php?name=Content \&pa=showpage\&pid=3\&page=8; last access: 14.01 .2014

9 Nationale Verzehrstudie II von 01/2008 des Bundesministeriums für Ernährung, Landwirtschaft und Verbraucherschutz. Ernährung 2008; 2: $77-81$

10 Marret H, Fauconnier A, Chabbert-Buffet $N$ et al. Clinical practice guidelines on menorrhagia: Management of abnormal uterine bleeding before menopause. Eur J Obstet Gynecol Reprod Biol 2010; 152: 133-137

11 Quinbi WY. The efficacy and safety of current intravenous iron preparations for the management of iron-deficiency anemia: a review. Arzneimittelforsch 2010; 60 (6a): 399-412

12 Liu Z, Doan QV, Blumenthal P et al. A systematic review evaluating health-related quality of life, work impairment, and health-care costs and utilization in abnormal uterine bleeding. Value Health 2007; 10 : 183-194

13 Pfenniger A, Schuller C, Christoph P et al. Safety and efficacy of high-dose iron carboxymaltose vs. iron sucrose for treatment of postpartum anaemia. J Perinat Med 2012; 40: 397-402

14 Muñoz M, Garcia-Erce A, Remacha AF. Disorders of iron metabolism. Part II: iron deficiency and iron overload. J Clin Pathol 2011; 64: 287296

15 Cook JD. Diagnosis and management of iron-deficiency anemia. Best Pract Res Clin Haematol 2005; 18: 319-323

16 Weiss G, Goodnough LT. Anemia of chronic disease. N Engl J Med 2005; 352: 1011-1023

17 Moreno F, Sanz-Guajardo D, Lopez-Gomez JM et al. Increasing the hematocrit has a beneficial effect on quality of life and is safe in selected hemodialysis patients: Spanish Cooperative Renal Patients Quality of Life Study Group of the Spanish Society of Nephrology. J Am Soc Nephrol 2000; 11: 335-342

18 Littlewood TJ, Bajetta E, Nortier JW et al. Effects of epoetin alfa on hematologic parameters and quality of life in cancer patients receiving non-platinum chemotherapy: results of a randomized, double blind, placebo-controlled trial. J Clin Oncol 2001; 19: 2865-2874

19 Van Wyck DB, Mangione A, Morrison J et al. Large-dose intravenous ferric carboxymaltose injections for iron deficiency anemia in heavy uterine bleeding: a randomized, controlled trial. Transfusion 2009; 49: 2719-2728

20 Dietzfelbinger $H$. Richtlinien zur Behandlung des Eisenmangels. Tempo Medical 1997; 19: 16-24

21 Dietzfelbinger $H$, Kaboth $W$, Theml $H$. Eisenmangelanämie. Intern Prax 1980; 20: 395-408

22 Hershko C, Skikne B. Pathogenesis and management of iron deficiency anemia: emerging role of celiac disease, Helicobacter pylori, and autoimmune gastritis. Seminars in Hematology 2009; 46: 339-350

23 Lipp HP. Peroral und intravenös anwendbare Eisenpräparate. Krankenhauspharmazie $2011 ; 32: 450-459$

24 Schaefer RM. Eisenmangel - mit und ohne Anämie - behandelt. Allgemeinarzt 2011; 18: 42-46
25 Bergmann RL, Dudenhausen JW, Ennen JC et al. Diagnostik und Behandlung der Anämie und des Eisenmangels in der Schwangerschaft und im Wochenbett. Literaturüberblick und Empfehlungen. Geburtsh Frauenheilk 2009; 69: 682-686

26 Link H. Anämie bei Krebs. Der Onkologe 2009; 2: 1-8

27 Beglinger C, Breymann C. Behandlung von Eisenmangel. Wie sind die praktischen Erfahrungen mit oralen und i.v. Eisenpräparaten? Schweiz Med Forum 2010; 10: 1-6

28 Geisser P. Pharmakologie und Sicherheitsprofil von Ferric Carboxymaltose $\left(\right.$ Ferinject $\left.{ }^{\circledR}\right)$ : Struktur/Reaktivitäts-Verhältnisse von Eisenpräparaten. Port J Nephrol Hypert 2009; 23: 11-16

29 Breymann C, Römer T, Dudenhausen JW. Treatment of iron deficiency in women. Geburtsh Frauenheilk 2013; 73: 256-261

30 Vifor Pharma. Fachinformation - ferinject ${ }^{\circledR}$, Oktober 2013

31 Quinbi W, Martinez C, Smith $M$ et al. A randomized controlled trial comparing intravenous ferric carboxymaltose with oral iron for treatment of iron deficiency anaemia of non-dialysis-dependent chronic kidney disease patients. Nephrol Dial Transplant 2011; 26: 1599-1607

32 Kulnigg S, Stoinov S, Simanenkov V et al. A novel intravenous iron formulation for treatment of anemia in inflammatory bowel disease: the ferric carboxymaltose (Ferinject ${ }^{\circledR}$ ) randomized controlled trial. Am J Gastroenterol 2008; 103: 1182-1192

33 Anker SD, Comin CJ, Filippatos G et al. Ferric carboxymaltose in patients with heart failure and iron deficiency. N Engl J Med 2009; 361: 24362448

34 Anker SD, Comin-Colet J, Filipatos G et al. Rationale and design of Ferinject ${ }^{\circledR}$ Assessment in patients with IRon deficiency and chronic Heart Failure (FAIR-HF) study: a randomized, placebo-controlled study of intravenous iron supplementation in patients with and without anaemia. Eur J Heart Fail 2009; 11: 1084-1091

35 Seid MH, Derman RJ, Baker BJ et al. Ferric carboxymaltose injection in the treatment of postpartum iron deficiency anemia: a randomized controlled clinical trial. Am J Obstet Gynecol 2008; 199: 435.e1-435.e7

36 Van Wyck DB, Martens MG, Seid MH et al. Intravenous ferric carboxymaltose compared with oral iron in the treatment of postpartum anemia. A randomized controlled trial. Obstet Gynaecol 2007; 110: 267278

37 Muñoz M, Martin-Montanez E. Ferric carboxymaltose for the treatment of iron deficiency anemia. Expert Opin Pharmacother 2012; 13: 907921

38 Breymann C, Glia F, Bejenariu C et al. Comparative efficacy and safety of intravenous ferric carboxymaltose in the treatment of postpartum iron deficiency anemia. Int J Gynecol Obstet 2008; 101: 67-73

39 Gesetz über den Verkehr mit Arzneimitteln (Arzneimittelgesetz AMG) in der Fassung vom 19.10.2012; http://www.gesetze-iminternet.de/bundesrecht/amg_1976/gesamt.pdf

40 Verband forschender Pharma-Unternehmen. Register nicht-interventioneller Studien. Online: http://www.vfa.de/de/arzneimittelforschung/datenbanken-zu-arzneimitteln/nisdb/nis-details/_551; last access: 14.01 .2014

41 European Medicines Agency EMEA. Guideline on pharmacovigilance practices. 2012. Online: www.ema.europa.eu/docs/en_GB/document _libery/scientific_guideline/2012/06/WC500129136.pdf; last access: 14.01.2014

42 Raspe F, Breymann C. Diagnosis and therapy of anaemia in pregnancy and puerperium - a survey of obstetric clinics in Switzerland. Geburtsh Frauenheilk 2011; 71: 595-600

43 Fletes R, Lazarus JM, Gage J et al. Suspected iron dextran-related adverse drug events in hemodialysis patients. Am J Kidney Dis 2001; 37 : 743-749

44 Sanofi Aventis. Ferrlecit summary of product characteristics. September 2013

45 Vifor Pharma Ltd. Venofer summary of product characteristics. September 2013

46 Crichton RR, Danielson BG, Geisser P. Iron Therapy - with special Emphasis on intravenous Administration. 4th ed. Bremen: UNI-Med; 2008: 71

47 Bailie GR. Breaking new ground in intravenous iron therapy. Eur Haematol Touch Briefings 2008; 2: 58-60

48 Van Wyck DB. Labile iron manifestations and clinical implications. J Am Soc Nephrol 2004; 15: 107-111 